\title{
INDIAN YOUTH POVERTY: A DISTRICT LEVEL ANALYSIS
}

Kaustav Misra, Saginaw Valley State University

Rima Chaudhuri, Heritage Institute of Technology

Surender Reddy, Saginaw Valley State University

dx.doi.org/10.18374/JABE-13-2.3

\begin{abstract}
India made significant progress on reducing poverty between 1981 and 2001. Although the number of people living on less than US $\$ 1$ a day has declined, it still is significantly large to merit considerable attention for antipoverty policy formulation. The paper determines the factors affecting youth poverty, employing district level data. Analysis of the results conclude that rural youth population needs more attention than urban youth population, the agricultural industry needs better infrastructure, and an effective educational program is essential to eradicate youth poverty from these states in India. Appropriate suggestions are made to policymakers who could help in minimizing the youth poverty in India.
\end{abstract}

Keywords: Young Adult, Youth Poverty, Poverty, India 